\title{
HYPERSENSITIVITY AND IMMUNITY REACTIONS AND CLASSIFICATION
}

The relationship between delayed hypersensitivity and immunity is a problem with a long and vexed history. Suffice it for the moment to say that delayed hypersensitivity and cell mediated immunity are closely interconnected, the two being operated by the same or related mechanisms. As regards leprosy, new light has been shed on this relationship, and also on the significance of the lymphocyte transformation test (LTT), by recent work at the Armauer Hansen Research Institute and the Medical Research Council Unit at Addis Ababa.

The TT-LL classification scale was originally intended to reflect resistance, immunity or whatever it was that determined the pattern of the disease; but whereas the middle and the repromatous end were soundly based, mainly on the rate of lysis or removal of Mycobacterium leprae in patients on chemotherapy, now known to be a function of cell mediated immunity, there had been no equivalent numerical index that could be applied to the tuberculoid end. It was hoped that the LTT using $M$. leprae antigen might fill this gap, and it was satisfactory therefore to find that the classification scale as originally defined (Ridley and Jopling, 1966) correlated tolerably well with the LTT (Myrvang et al., 1973a). The correlation, however, was with groups rather than individuals. Furthermore, it was found that the LTT was virtually negative in patients in the clinically indeterminate stage although many such cases are thought to be self-healing (Myrvang et al., 1973b). And when the test was applied to borderline patients in reaction some surprising results were obtained that could not be reconciled with shifts in immunity (Godal et al, 1973). A more detailed retrospective analysis of the histology of individual patients in the Myrvang et al., (1973a) series also produced surprising results (Ridley, 1974); because although the LTT confirmed most of the histological criteria it failed to correlate with the number of lymphocytes in the lesions which had been one of the pillars of the original classification. Allowing for the special relationship of $M$. leprae to nerve and also epidermis (Ridley, 1973), the features with which the LTT correlated were those of hypersensitivity (Epstein, 1973), All these findings were confirmed in a new prospective study at Addis Ababa in which different, more sophisticated techniques were employed for the LTT amd for the preparation of $M$. leprae antigens (Bjune et al., 1976). This study also confirmed that the LTT was raised during reactions in borderline patients, and demonstrated that this elevation far outweighed the differences in value from one part of the spectrum to another. At the termination of the reaction the LTT fell to its initial level, or lower, whether or not there had been any shift in immunity as judged by classification. The authors concluded (1) that the LTT reflected the destructive aspect of delayed hypersensitivity rather than the protective aspects of immunity, and (2) that although it had served to pin-point precisely the histological features of hypersensitivity in leprosy, the LTT was not a useful tool for the evaluation of individual patients. Not only are the results weighted unduly by the response to reactions, but the individual differences in non-reacting patients in a group are marked; many non-reacting BT patients give almost negative results for reasons that are not yet understood. The immunologists in the Addis Ababa team believe that hypersensitivity and immunity in leprosy may represent responses to separate bacterial antigens. This also in a different context is the view of Youmans (1975) who concludes a review: "delayed hypersensitivity and immunity to tuberculosis 
are entirely separate processes that are initiated by animals in response to various components of the tubercle bacillus". The basis for this conclusion was the finding that macrophage migration inhibition factor, which is correlated with tuberculin hypersensitivity, and mycobacterial inhibition factor which inhibits the multiplication of tubercle bacilli, are two separate lymphokines. It had already been found that tuberculin protein exhibited strong tuberculin sensitizing activity, whereas immunity appeared to be enhanced only by a polysacchoride fraction, not protein (Takahashi, 1969). The situation is probably not so simple as this, because the results were influenced not only by the presence of otherwise of adjuvant but also by the route of administration of the antigen; and Warren (1972) reports somewhat conflicting results. Nevertheless there is some foundation for a dual antigen hypothesis which, if confirmed, would indicate the possibility of producing a vaccine that selectively enhanced immunity alone. The dual antigen theory also gives food for thought about the nature of reactions and the basis of classification in leprosy.

Apart from the occasional ENL-lice reaction that may be seen in the BL region of the spectrum (Waters and Ridley, 1964; Karat et al., 1967), the great majority of reactions in borderline leprosy patients would appear to belong to Coombs and Gell type IV, i.e. delayed hypersensitivity reactions (DHR). They are always associated with a strong rise in the LTT, and more often than not they are followed by an increase in the histological features of delayed hypersensitivity, the elimination of bacilli and perhaps resolution of the lesion. There is some support here for the idea of two sorts of antigen in that $M$. leprae antigen appears to present differently according to whether it is in Schwann cell or macrophage, with corresponding differences in the LTT response during reversal reactions (Barnetson et al., 1975). In the case of the reversal reactions in BT patients that are being considered by these authors the onset could be explained by a sudden "exposure" of a few bacilli or by a release of a particular sort of antigen from them. But in the case of BL patients in whom there may have been millions of bacilli in the lesions before the reaction commenced it is hardly credible that the onset of DHR could be due to this mechanism; large amounts of antigen must have been exposed for some time beforehand. In such a situation a I)HR can most readily be explained by assuming an increase of delayed hypersensitivity in response to the reduction of the bacterial load to the point at which pre-existing antigen becomes "noticed". Conversely in untreated active infections there is normally a progressive fall in delayed hypersensitivity in parallel with the increase in the bacterial load so that DHR is not precipitated. But a delay in this desensitization process would again result in a temporary imbalance between hypersensitivity and bacterial load. This is perhaps the most likely explanation of the occasional reaction that is associated with downgrading. Thus viewing DHR as a whole it is difficult to escape the impression of a quantitative relationship between the level of hypersensitivity on the one hand and the amount of immunologically detected antigen on the other. Such a quantitative relationship was demonstrated in tuberculosis by Romer (1908) and Hamburger (1909), who found that the intensity of the hypersensitivity response was dependent on the amount of antigen administered. Thus the quantitative relationship would appear clinically to be as important as the different antigens hypothesis, though not necessarily incompatible with it.

Turning to classification, the foregoing results with the LTT raise a number of questions. Does the Ridley-Jopling scale reflect any sort of useful immunity or 
only a destructive hypersensitivity? Can the two in practice be separated in leprosy? And if so does the disease really present two spectra instead of one?

Taking the last question first, there is some histological evidence of a dual spectrum based on the presence of few or many lymphocytes in lesions. Thus BT tends to link with $\mathrm{BL}$ and $\mathrm{BB}$ with subpolar leproma. The main difference between these spectra seems to be that, other things being equal, the patient with many lymphocytes will be rather more resistant to downgrading without treatment and more likely to upgrade with treatment (Ridley, 1974). Perhaps because he is more likely to upgrade he is also more likely to react. But it is not possible to equate either of these situations with immunity as opposed to hypersensitivity. The slight modifications proposed for the histological definition of the tuberculoid end of the spectrum, being based on the LTT, further emphasize the hypersensitivity element in classification. But these proposals were only made because a search over many years had failed to disclose any group of histologically or clinically identifiable tuberculoid patients in whom there was a predisposition to resolution of an established infection without destructive DHR. In this respect leprosy appears to differ from cutaneous leishmaniasis, a disease with which it has many other points in common, but in which there is an apparent dissociation of delayed hypersensitivity and immunity. Thus the recidiva form in which hypersensitivity is maximal is non-self healing, though other forms with less hypersensitivity are self-healing (Turk et al., 1970; Bryceson et al., 1972). In leprosy uncomplicated self-healing may in fact come about in the early stage of the infection in a manner indicative of an immune process. Clinically such cases may be identifiable as tuberculoid though it is not possible to predict which tuberculoid or indeterminate patients will be self-healing. There is a need for a simple specific test of immunity. Histologically at this stage there is still as a rule no granuloma (Myrang et al., 1973b). Once a granuloma is manifest hypersensitivity tends to be more conspicuous than immunity. No doubt the one is associated with the other, but if there are cases in which immunity is high in relation to hypersensitivity there are no means of detecting them. Indeed, since $M$. leprae in the absence of hypersensitivity appears to be almost avirulent, and since it is neither a physical or chemical irritant, one might suppose that the granuloma which is the cause of tuberculoid symptomatology is almost wholly a reflection of hypersensitivity. Thus one cannot object too strongly if it turns out that classification, at least in the tuberculoid region, is likewise a reflection primarily of hypersensitivity. As things stand the patient with the best prognosis is the one with a TT histology and clinically the minimum extension of the disease. Here again a quantitative relationship between hypersensitivity and antigen is in evidence. The main reason why the antigenic load in leprosy so readily gets out of hand is presumably that bacilli remain hidden for too long in nerves. But another factor could be that $M$. leprae, being of low virulence, is only weakly immunogenic since these two characteristics appear to go together (Brehmer et al., 1969).

If the dual antigen concept points the way to a better vaccine and better skin test antigens, the association of hypersensitivity with antigenic load emphasizes the desirability of early treatment. It is sometimes said with some justification that in view of the medical and social problems a diagnosis of leprosy should not be made until it can be proved. But there are, of course, two reasons why an early lesion may remain dormant for long periods: either because it is self-healing, or because the bacilli remain immunologically undetected while they multiply and 
establish themselves. The price of delay in starting treatment is sometimes heavy.

\section{References}

Barnetson, R. St. C., Bjune, (i., Pearson, J. M. HI. and Kronval, (i. (1975). Antigenic heterogeneity of patients with reactions in borderline leprosy. Br. med. J. 4, 435.

Bjune, G., Barnetson, R. St. C., Ridley, D). S. and, Kronval, G. (1976). Lymphocyte transformation test in leprosy; correlation of the response with inflammation of lesions. Clin. exp. Immunol. (in press).

Brehmer, W., Barclay, W. R., Anacker, R. L., Milner, K. C., Ribi, E. and Tarmina, D. F. (1969). In Immunologisch bedeutsame Mykobacterienfraktionen. (Eds E. Freerksen, R. Fetting and J. H. Thumin). p.7. Stuttgart: (Gustav Fischer Verlag.

Bryceson, A. D. M., Preston, P. M., Bray, R. S. and Dumonde, D). C. (1972). Experimental cutaneous leishmaniasis. Clin. exp. Immunol. 10, 305.

Epstein, W. L. (1967). Granulomatous hypersensitivity. Progr. Allergy 11, 36.

Godal, T., Myrvang, B., Samuel, D. R., Ross, W. F. and L $\phi$ fgren, M. (1973). Mechanism of reactions in borderline (BT) leprosy. Acta path. microbiol. scand. Sect. A. Suppl. 236, 45.

Hamburger, F. (1909). Uber Tuberkuloseimmunitat. Beitr. klin. Tuberk. 12, 259.

Karat, A. B. A., Job, C. K. and Karat, S. (1967). Ery thema nodosum leprosum in borderline leprosy. Int. J. Lepr. 35, 17.

Myrvang, B., (iodal, T., Ridley, D. S., Froland, S. S. and Song, Y. K. (1973a). Immune responsiveness to Mycobacterium leprae and other mycobacterial antigens throughout the clinical and histopathological spectrum of leprosy. Clin. exp. Immunol. 14, 541.

Myrvang, B., Godal, T., Feek, C. M., Ridley, D. S. and Samuel, D. R. (1973b). Immune response to Mycobacterium leprae in indeterminate leprosy patients. Acta path. microbiol. scand. Section B 81, 615 .

Ridley, D. S. (1973). The pathogenesis of the early skin lesion in leprosy. J. Path. 111, 191.

Ridley, D. S. (1974). Histological classification and the immunological spectrum of leprosy. Bull. Wld Hlth Org. 51, 451 .

Ridley, D. S. and Jopling, W. H. (1966). Classification of leprosy according to immunity. Int. J. Lepr 34, 255.

Romer, P. H. (1908). Spezifische Überempfindlichkeit und Tuberkuloseimmunitat. Beitr. klin. Tuberk. 11, 79.

Takahashi, Y. (1969). In Immunologish bedeutsame Mykobacterien-Fraktionen. (Eds E. Freerksen, R. Fetting and J. H. Thumim). p. 10. Stuttgart: Gustav Fischer Verlag.

Turk, J. L., Bryceson, A. D. M. and Rees, R. J. W. (1970). A symposium: Leprosy and leishmaniasis. Proc. Roy. Soc. Med. 63, 1053.

Warren, K. S. (1972). In Inflammation (Eds. I. H. Lepow and P. A. Ward). p. 203. New York and London: Academic Press.

Waters, M. F. and Ridley, D. S. (1964). Necrotizing reactions in lepromatous leprosy. A clinical and histologic study. Int. J. Lepr. 31, 418.

Youmans, G. P. (1975). Editorial: Relation between delayed hypersensitivity and immunity in tuberculosis. Am. Rev. resp. Dis. $111,109$.

D. S. Ridley 